\title{
A Sharing Meanings Approach for Interdisciplinary Hazards Research
}

\section{R. Dean Hardy*}

*National Socio-Environmental Synthesis Center, University of Maryland College Park, 1 Park Place, Suite 300, Annapolis, MD 21401

\begin{abstract}
Hazards researchers frequently examine complex socio-environmental problems, a difficult undertaking which is further compounded by the challenge of navigating the many disciplinary approaches in the field. This paper draws on key insights from studies of the interdisciplinary process and proposes the Sharing Meanings Approach for improving interdisciplinary collaboration in hazards research. The Sharing Meanings Approach addresses common challenges to interdisciplinary teamwork and organizes them into four focal areas: (1) worldviews (including ontological, epistemological, and philosophical perspectives), (2) language, (3) research design, and (4) project goals. The approach emphasizes the process of sharing rather than seeking to develop a single set of shared meanings related to the four focal areas. The paper identifies common challenges and recommends strategies and actions within each focal area for guiding teams toward sharing their implicit meanings. A hypothetical example is introduced to demonstrate how the approach offers a path for revealing and overcoming the common roadblocks experienced in interdisciplinary hazards research. By making interdisciplinary hazards teams' implicit assumptions explicit, the Sharing Meanings Approach offers an operational process to seize on moments of difference as productive tension and to see such challenges as opportunities - rather than obstacles - for innovating toward hybrid methodological research designs in hazards research.
\end{abstract}

KEY WORDS: interdisciplinary, hazards, disasters, epistemology, Sharing Meanings Approach 


\section{INTRODUCTION}

Hazards researchers frequently examine complex socio-environmental problems, a difficult undertaking that is further compounded by the challenge of navigating the multitude of disciplinary approaches in the field. ${ }^{1}$ The hazards community is already multidisciplinary (Fuchs, Kuhlicke, \& Meyer, 2011; Wisner, 2004, 2016), however, an ISI Web of Science database search reveals limited discussion of interdisciplinary approaches in the hazards literature (Fig. 1). For clarity, interdisciplinary implies "integration that combines separate perspectives through the development of connections between them" contrasted with multidisciplinary signifying the same but without connections (Pennington et al., 2016). While interdisciplinary fields such as biodiversity conservation and socio-ecological systems already have interdisciplinary frameworks (e.g., Eigenbrode et al., 2017; Hirsch et al., 2013; Ostrom \& Cox, 2010), I contend that interdisciplinary teams of hazards researchers need such a framework that highlights guidance on sharing meanings; in other words, "the thing one intends to convey" to their team members (Merriam-Webster, 2017). I propose the Sharing Meanings Approach as a way forward for improving interdisciplinary collaboration in hazards research.

\section{THE SHARING MEANINGS APPROACH}

Drawing key insights from studies of the interdisciplinary research process (Campbell, 2005; Eigenbrode et al., 2007; Klein, 2008; Lélé \& Norgaard, 2005; Looney et al., 2014; National Research Coucil, 2015; Palmer, Kramer, Boyd, \& Hawthorne, 2016; Read et al., 2016; Star, 2010a), the Sharing Meanings Approach addresses common challenges to interdisciplinary teamwork and organizes them into four focal areas: (1) worldviews (including ontological, epistemological, and philosophical perspectives), (2) language, (3) research design, and (4) project goals (Table I). Rather than seeking to develop a single set of shared meanings for the four areas, the Sharing Meanings Approach emphasizes an iterative process of sharing (Fig. 2). The emphasis on process is meant to elicit the "productive tension" of different worldviews and methodologies that in turn may lead to novel insights and discoveries in research endeavors (Nightingale, 2016). Indeed, more than needing to defend terms, develop shared definitions, or agree upon a single or best worldview is the need to develop a process where team members make their implicit meanings explicit. The approach is not intended to be followed in a step-wise manner, but is meant to serve as a flexible guide for interdisciplinary teams designing and doing research. A focus on worldviews comes first followed by an iterative process between the other three focal areas, particularly the research design and project goal areas. The Sharing Meanings Approach is a call to make sharing — but also listening — an explicit practice within interdisciplinary hazards research.

\subsection{Worldviews}

Beyond disciplines, divergent worldviews often act as hidden barriers for people working in teams (Eigenbrode et al., 2007; Fuchs et al., 2011; Wisner, 2016). I define worldview as being inclusive of (1) a person's perspective on what exists in the world (i.e., ontology), (2) how a person comes to know and understand what exists (i.e., epistemology), and (3) whether a person

\footnotetext{
${ }^{1}$ While approaches to hazards mitigation, disaster risk reduction, and climate change adaptation differ in temporal scales, knowledge bases, and norm systems, they are interrelated (Birkmann \& von Teichman, 2010). I will refer to them collectively as "hazards research" for simplicity unless specifically referencing a specific literature.
} 
believes their research is value-laden (i.e., philosophical perspective) (Moon \& Blackman, 2014). Our worldviews underpin the theoretical and methodological commitments that we make in our research. Such commitments are informed by, for example, a belief that either value-free objective research is possible, or in contrast, that all perspectives are partial and all knowledge is value-laden and situated within specific contexts (Haraway, 1988). Our commitments can create roadblocks for collaboration that may persist whether a project involves purely academic investigation, on-the-ground hazard mitigation planning, or disaster response and recovery efforts (Frazier, Walker, Kumari, \& Thompson, 2013; Fuchs et al., 2011). Implicit worldviews may act as silent disruptors to team progress and success if the focus is only on managing differences in disciplines rather than on the deeper context of revealing divergent worldviews.

It is important to underscore that most research fields (even disciplines) are not as homogeneous as many scholars may believe. There is a spectrum of worldviews among and within disciplines ranging from realist to relativist ontologies, objective to subjective epistemologies, and positivist to constructivist philosophical perspectives. ${ }^{2}$ Recognizing and managing these differences will be challenging. As Lélé and Norgaard observe, "[n]atural scientists [or engineers in hazards research] need to expect to take considerable time learning the cultures of the different social sciences if they are even to think about how to put together or join an interdisciplinary team, let alone actually work with the social science members of the team" (Lélé \& Norgaard, 2005, p. 970). I would add that social scientists should equally learn that engineering and physical sciences are not as homogeneous as many social scientists may believe. If teams wait until the final stages of a project to discuss their divergent worldviews, "the chance that [such] challenges will be embraced as 'opportunities' is reduced" (Campbell, 2005, p. 575).

For sharing worldviews with team members as well as for raising self-awareness of one's own worldview, activities that elicit structured dialogue are needed. In practice, social scientists may have had more experience with discussions on worldviews as this is often a core part of their training, although to varying degrees. However, one field-tested example broadly designed to be inclusive of all STEM fields comes via the Toolbox Project, which offers the Toolbox instrument - six modules each with a core question and probing statements - in the Toolbox workshop (self-guidable, but preferably facilitated) lasting two to three hours (Eigenbrode et al., 2007; Looney et al., 2014). The Toolbox instrument aids communication by providing structured dialogue to reveal worldviews and their associated values while serving as a boundary object, or a "means of translation" across social worlds (Looney et al., 2014; Star \& Griesemer, 1989). Another activity that builds trust and improves communication is sharing a mental model of your work with the team, where a mental model is a "cognitive simplification of reality that is formulated through experience and is relatively stable" (Pennington et al., 2016). Take 15 minutes to draw a mental model of your individual research program, breakout into small groups, and explain your research diagram to others. Then have one of your collaborators explain it back to you. The developers of these activities have found that they improve communication (Looney et al., 2014; Pennington et al., 2016).

\subsection{Language}

Communication is a major hurdle in team science, especially interdisciplinary teams (National Academies of Science, 2005; Read et al., 2016). One of the more salient concerns

\footnotetext{
${ }^{2}$ For an extensive discussion of ontology, epistemology, and philosophical perspective, see Moon and Blackman's (2014) review article in Conservation Biology, "A Guide to Understanding Social Science Research for Natural Scientists.” Also see Eigenbrode et al. (2007).
} 
regarding communication within interdisciplinary collaborations is shared language. We may "use the same words with different meanings, associated with different historical lineages" (Lélé \& Norgaard, 2005, p. 970). Vulnerability is a colloquial word used in everyday talk, for example, one that is employed by multiple disciplines to describe the potential for harm to things ranging from physical structures to human populations. The popularity of vulnerability in the scholarly literature has grown rapidly over the past few decades including in the literature on climate change (Tschakert, van Oort, St. Clair, \& LaMadrid, 2013; Westcoat, 2015; Wisner, 2016). The number of records that mention the topic of vulnerability in the ISI Web of Science database increased more than $150 \%$ over the past decade, reaching over 10,000 records per year during the past three years - and in the hazards and disasters literature specifically, that number has exceeded 1,100 records per year. Such rapid growth across the social, natural, and physical sciences has led to a diversity of definitions and frameworks in environmental and climaterelated hazards research (Eakin \& Luers, 2006; Füssel, 2007; Gallopín, 2006; O’Brien, Eriksen, Nygaard, \& Schjolden, 2007; Otto et al., 2017; Ribot \& Peluso, 2003; Smit \& Wandel, 2006; Turner et al., 2003; Wisner, 2016). While such wide usage reveals the potential for miscommunication and confusion within teams, it importantly conveys the power and potential that the multi-dimensional concept of vulnerability possesses for facilitating interdisciplinary hazards research.

In addition to shared language with different meanings being a challenge, shared definitions with different language may also occur; for example, the terms "leaders" and "stakeholders" may be used by different fields to mean the same group of people. Different disciplines and even areas of specialty within disciplines have their own language for discussing these and other concepts. Without explicitly sharing meanings related to language, these differences may stay masked and cause confusion. The Sharing Meanings Approach is intended to unmask these differences by operationalizing the act of sharing and communicating language in interdisciplinary hazards research.

One strategy for managing confusion around language is using an interactive (in the meeting space, but preferably online) "jargon board" where members can post unfamiliar terms they hear during discussion. ${ }^{3}$ Additionally, a jargon board would be a space for members to post terms that are being used differently from their own definition, which would make space for the team to return to those terms and define their multiple usages by the team. A related second activity is defining terms that make it onto the jargon board by co-creating and co-writing a team glossary in a more permanent space. For both activities, there are numerous online platforms that could be used to facilitate collaboration among teams. Sharing worldviews and language improves communication that facilitates creating interdisciplinary research, but designing such research is its own challenge.

\subsection{Research Design}

Research designs are distinct from the idea of "interdisciplinary methods," which presupposes that methods are disciplinary. Many disciplines are dependent upon specific methods (e.g., ethnography in cultural anthropology), but many methods are already used by multiple disciplines. Rather than a focus on methods, researchers from within risk, hazards, and climate change adaptation studies have called for more approaches that are inter-epistemological with teams comprising different ways of knowing problems and seeking to create hybrid

\footnotetext{
${ }^{3}$ An online jargon board will provide a more discreet space for posting, and hopefully increase the chance that team members will post terms that they do not know or understand.
} 
methodologies (Healy, 2003, 2004; Murphy, 2011; Nightingale, 2003, 2016; Popke, 2016). I want to clarify the difference in how I am applying "method" and "methodology" in this paper. I define method as an individual tool or technique for examining something, whereas methodology is defined as a suite of methods for analyzing a complex issue.

A hybrid methodology then is a research design that comprises a suite of methods that cut across disciplines, sub-disciplines, and importantly even worldviews (Nightingale, 2016). It does not supplant traditional methods, but instead calls for explicitly sharing what each method brings to a particular research challenge. The call for a hybrid methodology research design seeks to overcome the challenge of partial understandings that are inherent to single discipline perspectives on complex socio-environmental challenges. "A hybrid method[ology] research design requires thinking through what can be known and also what cannot be known by using a particular method" (Nightingale, 2016, p. 42). The objective is to share how each method may contribute to other methods synergistically rather than additively (Pennington et al., 2016), while also recognizing that the results will not always match. "Researchers should expect that results in an interdisciplinary research design will produce silences between data sets (Fielding, 2012), and it is precisely in probing these gaps that important new insights emerge" (Nightingale, 2016, p. 42).

The Sharing Meanings Approach calls for interdisciplinary teams to develop hybrid methodologies that explicitly connect the worldviews and technical skills of team members. To achieve this, teams must define a shared research problem by co-developing a shared mental model through "iterative individual external representations of the problem" (Pennington et al., 2016, p. 278). Mental models are individual, internal simplifications of reality, whereas shared mental models are "emergent, distributed cognitive states that are generated in real time in a specific context and reflect shared understanding of a problem... and evolve as group understanding evolves." (Pennington et al., 2016, p. 280) Shared mental models effectively function as boundary objects (Star, 2010b), or boundary negotiating objects over which teams move through iterative sharing of individual mental models to form an external, evolving shared mental model (Pennington et al., 2016). This process of sharing can build trust and a collective communication competence among science teams (Read et al., 2016; Thompson, 2009), improving the likelihood of success.

\subsection{Project Goals}

Deeply intertwined with research design decisions are project goals, which ideally would meet expectations of all team members as project goals are likely the motivating factor for many members' participation (Palmer et al., 2016; Pennington, Simpson, McConnell, Fair, \& Baker, 2013). If teams consist of collaborators with disparate motivations regarding individual goals, making those differences explicit early in the project will improve communication and ultimately project outcomes. The Sharing Meanings Approach highlights three topics for action regarding project goals: project objectives, project deliverables, and authorship expectations and needs. These areas can be addressed in tandem with the shared mental model activity described under research design and/or in separate sharing sessions explicitly focused on each topic.

One common challenge among interdisciplinary hazards teams is having a shared broad level objective such as mitigating vulnerability, but with divergent specific objectives such as minimizing harm to physical infrastructure versus increasing adaptive capacity of marginalized households. Having shared broad level objectives is necessary, but not sufficient for project success. The Sharing Meanings Approach calls for action by having team members identify and list their specific objectives for meeting the broader objective. This has two positive effects. 
First, team members are motivated and encouraged to consciously acknowledge their own specific objectives to themselves. Second, sharing of these lists will facilitate structured discussion among teams about prioritizing specific objectives and who can assist with achieving each one.

Two other common challenges include team members having different desires for project deliverables (e.g., journal articles, reports, white papers, datasets, policy recommendations, etc.) and managing publication expectations. These are key topics to discuss early in an interdisciplinary hazards project because team members come from disciplines or fields with different expectations regarding deliverables. Some disciplines count publications in interdisciplinary journals toward tenure, whereas others value discipline-specific publications. This can be of particular concern for junior faculty, and likely of little to no concern for practitioners who are not bound by the "publish or perish" mantra. Moreover, the qualitative social sciences lean toward sole-authorship or minimal authors as more favorable, whereas the natural and physical sciences are more accepting of many-authored papers (Campbell, 2005). With article metrics counting more with tenure-track search committees as well as tenure and promotion committees, post-graduates and junior faculty are increasingly challenged to publish high impact articles in their relevant fields (Leahey, 2016; Rhoten \& Parker, 2004). Discussing and listing project deliverables and publication expectations early and often will improve transparency and communication.

Negotiating within each of these three topics (and the research design activity) may create conflict among team members. Having one or several project team members that are trained in conflict management as well as facilitation strategies will likely improve trust and communication within hazards teams (Read et al., 2016). In fact, "[s]killful management of conflict can harness and convert it in some cases into a "constructive force"" (Read et al., 2016). Moreover, not only are interdisciplinary teams in need of members with the above skills, but they also need members trained with the "agility" to connect disciplinary perspectives and worldviews (see Welch-Devine, Hardy, Brosius, \& Heynen, 2014).

\section{A HYPOTHETICAL EXAMPLE}

To illustrate the utility of the Sharing Meanings Approach, I employ a hypothetical example in which an interdisciplinary team is tasked with hazard mitigation planning for a coastal city. All team members share the project's broad objective to reduce vulnerability to storm surge, however, this obscures the differences that exist among team members due to implicit assumptions. The recommended strategies and actions listed in the Sharing Meanings Approach are intended to facilitate communication and information sharing while also revealing many of those hidden assumptions.

Early in the project, the team works on trust building through relationship development and information transaction (Read et al., 2016). They begin with the worldview focal area activities, which initially includes diagraming and sharing individual mental models of their own work. This activity identifies one group with expertise in assessing physical vulnerability and another group with expertise in examining social vulnerability. For simplicity, I broadly classify these groups and label them as 'Group Blue' and 'Group Green', respectively (Table II). During the Toolbox Project workshop, the structured discussion of value and objectivity reveals that the groups' differences are more than physical versus social vulnerability, but a divergence of worldviews. Group Blue fits into an objectivist epistemology - one where the assumption is that there is a material world that can be observed and measured in a manner free of any human

values or subjective biases. In contrast, Group Green fits into a constructivist epistemology—one 
where the assumption is that all knowledge is value-laden and subjective; in other words, all knowledge is socially influenced. ${ }^{4}$

Both groups' worldviews are pertinent for mitigating vulnerability of the city to storm surge; however, their different worldviews affect not only the questions they think are important to ask, but also the methods they choose to include in their research design and their project goals. To create a hybrid methodology research design, the team iteratively develops a shared mental model that captures Group Blue's interest in asking what is the location of the most physically vulnerable infrastructure relative to the hydrological forces of storm surge? Their list of specific objectives includes locating the most vulnerable infrastructure and designing solutions that mitigate damage and losses to houses, schools, roads, bridges, and other infrastructure. Group Blue lists methods that include mapping the statistical probability of flooding from storm surge and assessing the tolerance and integrity of potentially exposed infrastructure (e.g., Agarwal, Blockley, \& Woodman, 2003; Lin, Emanuel, Smith, \& Vanmarcke, 2010; Lind, 1995).

In contrast, the process of developing a shared mental model uncovers Group Green's interest in asking why are some households more socially vulnerable to storm surge? Their specific objectives of interest are identifying the most socially vulnerable households-defined as a household's ability to prepare for, respond to, and recover from storm surge - and designing policy strategies to mitigate social vulnerability in the city. They propose a list of methods that include a socio-economic survey of households and interviews with heads of households. These data would be analyzed by examining the broader socio-political context for chains of causality that increase social vulnerability (e.g., Ribot \& Peluso, 2003; Wisner, 2004; Wisner, Blaikie, Cannon, \& Davis, 2004).

Both groups' approaches would move the city towards mitigating its overall vulnerability to storm surge, however, their approaches are clearly focused on different domains. The project goals of these two groups are different due to their worldviews, but also the timeframe that each group is considering. Group Blue aims to protect property and infrastructure as well as people's safety within a planning horizon of five to 30 years. Group Green aims to identify - and ideally transform - the underlying social structures and institutions that cause uneven vulnerability to hazards across social difference, in part by being inclusive through "opening the space for local experience" in the incremental process of societal transformation (Gibson \& Wisner, 2016). Group Green wants to contribute to knowledge that reveals how social institutions in a society perpetuate inequity and uneven vulnerability with a goal of informing policy that leads to immediate action and permanent societal changes.

Through the strategies and actions recommended by the Sharing Meanings Approach, the team is better capable of explicitly acknowledging their differences. The team is empowered to both mitigate imminent vulnerability due to physical flooding, but also to contribute toward mitigating the underlying causes of uneven vulnerability across social difference. The team could agree on a hybrid methodology research design that investigated flood risk and infrastructure integrity in areas with socially vulnerable populations. The team could even agree to recommend that the city target infrastructural improvements to areas with disproportionate degrees of

\footnotetext{
${ }^{4}$ Objective and subjective views need not always map onto physical and social sciences, respectively. Indeed, much of social science is objective in its epistemological framing (e.g., social vulnerability indices) and emerging research in physical sciences is acknowledging its subjectivity (e.g. Lave, Biermann, \& Lane, 2018). Such delineations will be murkier in practice.
} 
socially vulnerable populations while developing policy recommendations that work toward eliminating social vulnerability.

\section{CONCLUDING THOUGHTS}

The Sharing Meanings Approach is tough work. It requires more time and intellectual investment by team members. It demands a commitment to listening to what other team members are intending to convey. Moreover, it is not a call to debate semantics or a call for teams to decide on a single best worldview. This would significantly undermine the potential productivity of working in an interdisciplinary team with multiple worldviews. On the contrary, by making the implicit assumptions of the team explicit, the Sharing Meanings Approach offers an operational process to seize on those moments of difference as "productive tension" and to see such challenges as opportunities for innovating toward a hybrid methodology research design (Campbell, 2005; Nightingale, 2016; Popke, 2016). Such differences, even practical hurdles that occur when working in interdisciplinary teams, can be innovative moments if properly managed by team leaders or outside facilitators (Palmer et al., 2016). Piers Blaikie's work on the political economy of soil erosion in West Africa is a classic example of successful interdisciplinary investigation in hazards research (Blaikie, 1985). Blaikie's work embraced not only a hybrid methodology research design, but also epistemological pluralism (Forsyth, 2008). I believe that the Sharing Meanings Approach could foster similar successes within the hazards research community. 


\section{ACKNOWLEDGEMENTS}

This work was supported by the National Socio-Environmental Synthesis Center (SESYNC) under funding received from the National Science Foundation (Award \#DBI1639145) as well as under funding received for a workshop on Interdisciplinary Methods for Disasters Research (NSF Award \#1650202)

\section{REFERENCES}

Agarwal, J., Blockley, D., \& Woodman, N. (2003). Vulnerability of structural systems. Structural Safety, 25(3), 263-286. https://doi.org/10.1016/S0167-4730(02)00068-1

Birkmann, J., \& von Teichman, K. (2010). Integrating disaster risk reduction and climate change adaptation: Key challenges-scales, knowledge, and norms. Sustainability Science, 5(2), 171-184. https://doi.org/10.1007/s11625-010-0108-y

Blaikie, P. (1985). The political economy of Soil Erosion in developing countries (1st Editio). Routledge.

Campbell, L. M. (2005). Overcoming Obstacles to Interdisciplinary Research. Conservation Biology, 19(2), 574-577. https://doi.org/10.1111/j.1523-1739.2005.00058.x

Eakin, H., \& Luers, A. L. (2006). Assessing the vulnerability of social-environmental systems. Annual Review of Environment and Resources, 31, 365-394.

Eigenbrode, S. D., Martin, T., Morton, L. W., J. Colletti, P. G., Gustafson, R., Hawthorne, D., ... Wolcott, M. (2017). Leading large transdisciplinary projects addressing social-ecological systems : A primer for project directors. https://doi.org/10.7923/G4HM56GJ

Eigenbrode, S. D., O'Rourke, M., Wulfhorst, J. D., M, A. D., Godlberg, C. S., Merrill, K., ... Bosque-Perez, N. A. (2007). Employing Philosophical Dialogue in Collaborative Science. BioScience, 57(1), 55. https://doi.org/10.1641/B570109

Fielding, N. G. (2012). Triangulation and Mixed Methods Designs: Data Integration With New Research Technologies. Journal of Mixed Methods Research, 6(2), 124-136. https://doi.org/10.1177/1558689812437101

Forsyth, T. (2008). Political ecology and the epistemology of social justice. Geoforum, 39(2), 756-764. https://doi.org/10.1016/j.geoforum.2006.12.005

Frazier, T. G., Walker, M. H., Kumari, A., \& Thompson, C. M. (2013). Opportunities and constraints to hazard mitigation planning. Applied Geography, 40, 52-60. https://doi.org/http://dx.doi.org/10.1016/j.apgeog.2013.01.008

Fuchs, S., Kuhlicke, C., \& Meyer, V. (2011). Editorial for the special issue: Vulnerability to natural hazards-the challenge of integration. Natural Hazards, 58(2), 609-619. https://doi.org/10.1007/s11069-011-9825-5

Füssel, H.-M. (2007). Vulnerability: a generally applicable conceptual framework for climate change research. Global Environmental Change, 17(2), 155-167.

Gallopín, G. C. (2006). Linkages between vulnerability, resilience, and adaptive capacity. Global Environmental Change, 16(3), 293-303.

Gibson, T., \& Wisner, B. (2016). "Lets talk about you ...”: Opening space for local experience, action and learning in disaster risk reduction. Disaster Prevention and Management: An International Journal, 25(5), 664-684. https://doi.org/10.1108/DPM-06-2016-0119

Haraway, D. (1988). Situated knowledges: The science question in feminism and the privilege of partial perspective. Feminist Studies, 14(3), 575-599.

Healy, S. (2003). Epistemological pluralism and the 'politics of choice.' Futures, 35(7), 689- 
701. https://doi.org/10.1016/S0016-3287(03)00022-3

Healy, S. (2004). A 'post-foundational' interpretation of risk: Risk as 'performance.' Journal of Risk Research, 7(3), 277-296. https://doi.org/10.1080/1366987042000176235

Hirsch, P. D., Brosius, J. P., O'Conner, S., Zia, A., Welch-Devine, M., Dammert, J. L., ... McShane, T. O. (2013). Navigating Complex Trade-offs in Conservation and Development: an Integrative Framework. Issues in Interdisciplinary Studies, (31), 99-122. Retrieved from http://hdl.handle.net/10323/4482

Klein, J. T. (2008). Evaluation of interdisciplinary and transdisciplinary research. American Journal of Preventive Medicine, 35(2), S116-S123.

Lave, R., Biermann, C., \& Lane, S. N. (2018). Introducing Critical Physical Geography. In The Palgrave Handbook of Critical Physical Geography (pp. 3-21). Springer.

Leahey, E. (2016). From Sole Investigator to Team Scientist: Trends in the Practice and Study of Research Collaboration. Annual Review of Sociology, 42(1), 81-100. https://doi.org/10.1146/annurev-soc-081715-074219

Lélé, S., \& Norgaard, R. B. (2005). Practicing interdisciplinarity. Bioscience, 55(11), 967-975. https://doi.org/10.1641/0006-3568(2005)055[0967:pi]2.0.co;2

Lin, N., Emanuel, K. A., Smith, J. A., \& Vanmarcke, E. (2010). Risk assessment of hurricane storm surge for New York City. Journal of Geophysical Research, 115(D18121), 1-11. https://doi.org/10.1029/2009JD013630

Lind, N. C. (1995). A measure of vulnerability and damage tolerance. Reliability Engineering and System Safety, 48(1), 1-6. https://doi.org/10.1016/0951-8320(95)00007-O

Looney, C., Donovan, S., O'Rourke, M., Crowley, S., Eigenbrode, S. D., Rotschy, L., ... Wulfhorst, J. D. (2014). Seeing Through the Eyes of Collaborators. In M. O'Rourke, S. Crowley, S. D. Eigenbrode, \& J. D. Wulfhorst (Eds.), Enhancing Communication and Collaboration in Interdisciplinary Research (pp. 220-243). Sage Publishing.

Merriam-Webster. (2017). Definition of meaning. Retrieved June 30, 2017, from https://www.merriam-webster.com/

Moon, K., \& Blackman, D. (2014). A guide to understanding social science research for natural scientists. Conservation Biology, 28(5), 1167-1177. https://doi.org/10.1111/cobi.12326

Murphy, B. L. (2011). From interdisciplinary to inter-epistemological approaches: Confronting the challenges of integrated climate change research. Canadian Geographer / Le Géographe Canadien, 55(4), 490-509. https://doi.org/10.1111/j.1541-0064.2011.00388.x

National Academies of Science. (2005). Facilitating Interdisciplinary Research. Washington, D.C.: National Academies Press. Retrieved from http://www.nap.edu/catalog/11153

National Research Coucil. (2015). Enhancing the Effectiveness of Team Science. (Committee on the Science of Team Science, N. J. Cooke, \& M. L. Hilton, Eds.). Washington, D.C.: National Academies Press. https://doi.org/10.17226/19007

Nightingale, A. J. (2003). A feminist in the forest: Situated knowledges and mixing methods in natural resource management. ACME: An International E-Journal for Critical Geographies, 2(1), 77-90.

Nightingale, A. J. (2016). Adaptive scholarship and situated knowledges? Hybrid methodologies and plural epistemologies in climate change adaptation research. Area, 48(1), 41-47. https://doi.org/10.1111/area.12195

O’Brien, K. L., Eriksen, S., Nygaard, L. P., \& Schjolden, A. (2007). Why different interpretations of vulnerability matter in climate change discourses. Climate Policy, 7(1), $73-88$. 
Ostrom, E., \& Cox, M. (2010). Moving beyond panaceas: a multi-tiered diagnostic approach for social-ecological analysis. Environmental Conservation, 37(4), 451-463. https://doi.org/10.1017/s0376892910000834

Otto, I. M., Reckien, D., Reyer, C. P. O., Marcus, R., Le Masson, V., Jones, L., ... Serdeczny, O. (2017). Social vulnerability to climate change: A review of concepts and evidence. Regional Environmental Change, 1-12. https://doi.org/10.1007/s10113-017-1105-9

Palmer, M. A., Kramer, J. G., Boyd, J., \& Hawthorne, D. (2016). Practices for facilitating interdisciplinary synthetic research: The National Socio-Environmental Synthesis Center (SESYNC). Current Opinion in Environmental Sustainability, 19, 111-122. https://doi.org/http://dx.doi.org/10.1016/j.cosust.2016.01.002

Pennington, D. D., Bammer, G., Danielson, A., Gosselin, D., Gouvea, J., Habron, G., ... Wei, C. (2016). The EMBeRS project: employing model-based reasoning in socio-environmental synthesis. Journal of Environmental Studies and Sciences, 6(2), 278-286. https://doi.org/10.1007/s13412-015-0335-8

Pennington, D. D., Simpson, G. L., McConnell, M. S., Fair, J. M., \& Baker, R. J. (2013). Transdisciplinary Research, Transformative Learning, and Transformative Science. BioScience, 63(7), 564-573. https://doi.org/10.1525/bio.2013.63.7.9

Popke, J. (2016). Researching the hybrid geographies of climate change: Reflections from the field. Area, 48(1), 2-6. https://doi.org/10.1111/area.12220

Read, E., O’Rourke, M., Hong, G. S., Hanson, P. C., Winslow, L. A., Crowley, S., ... Weathers, K. C. (2016). Building the Team for Team Science. Ecosphere, 7(3), 1-9. Retrieved from https://doi.org/10.1002/ecs2.1291

Rhoten, D., \& Parker, A. (2004). Risks and Rewards of an Interdisciplinary Research Path. Science, 306(5704), 2046. https://doi.org/10.1126/science.1103628

Ribot, J. C., \& Peluso, N. L. (2003). A theory of access. Rural Sociology, 68(2), 153-181. https://doi.org/10.1111/j.1549-0831.2003.tb00133.x

Smit, B., \& Wandel, J. (2006). Adaptation, adaptive capacity and vulnerability. Global Environmental Change, 16(3), 282-292. https://doi.org/10.1016/j.gloenvcha.2006.03.008

Star, S. L. (2010a). This is Not a Boundary Object: Reflections on the Origin of a Concept. Science, Technology, \& Human Values, 35(5), 601-617. https://doi.org/10.1177/0162243910377624

Star, S. L. (2010b). This is Not a Boundary Object: Reflections on the Origin of a Concept. Science, Technology, \& Human Values, 35(5), 601-617. https://doi.org/10.1177/0162243910377624

Star, S. L., \& Griesemer, J. R. (1989). Institutional Ecology, 'Translations' and Boundary Objects: Amateurs and Professionals in Berkeley's Museum of Vertebrate Zoology, 190739. Social Studies of Science, 19(3), 387-420.

Thompson, J. L. (2009). Building Collective Communication Competence in Interdisciplinary Research Teams. Journal of Applied Communication Research, 37(3), 278-297. https://doi.org/10.1080/00909880903025911

Tschakert, P., van Oort, B., St. Clair, A. L., \& LaMadrid, A. (2013). Inequality and transformation analyses: A complementary lens for addressing vulnerability to climate change. Climate and Development, 5(4), 340-350. https://doi.org/10.1080/17565529.2013.828583

Turner, B. L., Kasperson, R. E., Matson, P. A., McCarthy, J. J., Corell, R. W., Christensen, L., ... Schiller, A. (2003). A framework for vulnerability analysis in sustainability science. 
Proceedings of the National Academy of Sciences, 100(14), 8074-8079. https://doi.org/10.1073/pnas.1231335100

Welch-Devine, M., Hardy, D., Brosius, J. P., \& Heynen, N. (2014). A pedagogical model for integrative training in conservation and sustainability. Ecology and Society, 19(2), 7. https://doi.org/10.5751/ES-06197-190210

Westcoat, J. (2015). Risk, hazards and vulnerability. In T. Perreault, G. Bridge, \& J. McCarthy (Eds.), The Routledge handbook of political ecology (pp. 293-319). London: Routledge.

Wisner, B. (2004). Assessment of capability and vulnerability. In G. Bankoff, G. Frerks, \& D. Hilhorst (Eds.), Mapping vulnerability: Disasters, development and people. (pp. 183-193). Sterling, VA: Earthscan.

Wisner, B. (2016). Vulnerability as concept, model, metric, and tool. In Oxford Research Encyclopedia of Natural Hazard Science (pp. 1-52). https://doi.org/10.1093/acrefore/9780199389407.013.25

Wisner, B., Blaikie, P., Cannon, T., \& Davis, I. (2004). At Risk: Natural Hazards, People's Vulnerability and Disasters (2nd ed.). Routledge. 
Table I. Four focal areas addressing common challenges in interdisciplinary research.

\begin{tabular}{|c|c|}
\hline $\begin{array}{l}\text { FOCAL } \\
\text { AREAS }\end{array}$ & $\begin{array}{l}\text { COMMON } \\
\text { CHALLENGES }\end{array}$ \\
\hline Worldviews & $\begin{array}{l}\text { - Hidden divergent values and beliefs about scientific research } \\
\text { - Different theoretical and methodological commitments }\end{array}$ \\
\hline Language & $\begin{array}{l}\text { - Communication and language "policing" } \\
\text { - Shared language with different definitions } \\
\text { - Shared definition with different language }\end{array}$ \\
\hline Research & - Methods considered to be disciplinary \\
\hline Design & - Developing an interdisciplinary research design \\
\hline $\begin{array}{l}\text { Project } \\
\text { Goals }\end{array}$ & $\begin{array}{l}\text { - Motivations for project participation } \\
\text { - Shared broad objectives with divergent specific objectives } \\
\text { - Different expectations and needs regarding deliverables }\end{array}$ \\
\hline
\end{tabular}


Table II. An interdisciplinary hazards team with divergent worldviews, shared (and not shared) language, different methods to contribute to research design, and different project goals.

\begin{tabular}{l|ll}
\hline FOCAL AREA & TEAM 'BLUE' & TEAM 'GREEN' \\
\hline Worldview & $\begin{array}{l}\text { Limiting physical exposure to flooding } \\
\text { is necessary to reduce vulnerability. }\end{array}$ & $\begin{array}{l}\text { Transforming the social institutions } \\
\text { that underserve specific social groups } \\
\text { is needed to reduce vulnerability. } \\
\text { Language }\end{array}$ \\
$\begin{array}{l}\text { (Physical) vulnerability; (topographic) } \\
\text { (Social) vulnerability; (household) } \\
\text { surveys; (social) disaster. }\end{array}$ \\
Research Design & $\begin{array}{l}\text { Infrastructure mapping; hydrodynamic } \\
\text { modeling; flood inundation mapping. }\end{array}$ & $\begin{array}{l}\text { Interviews; focus groups; demographic } \\
\text { modeling and mapping. }\end{array}$ \\
& $\begin{array}{l}\text { Limit physical damage to homes and } \\
\text { other infrastructure from flooding; } \\
\text { multi-authored articles. }\end{array}$ & $\begin{array}{l}\text { Identify pathways to reduce social } \\
\text { inequality and improve social equity; } \\
\text { solo or dual authored articles. }\end{array}$ \\
\hline
\end{tabular}




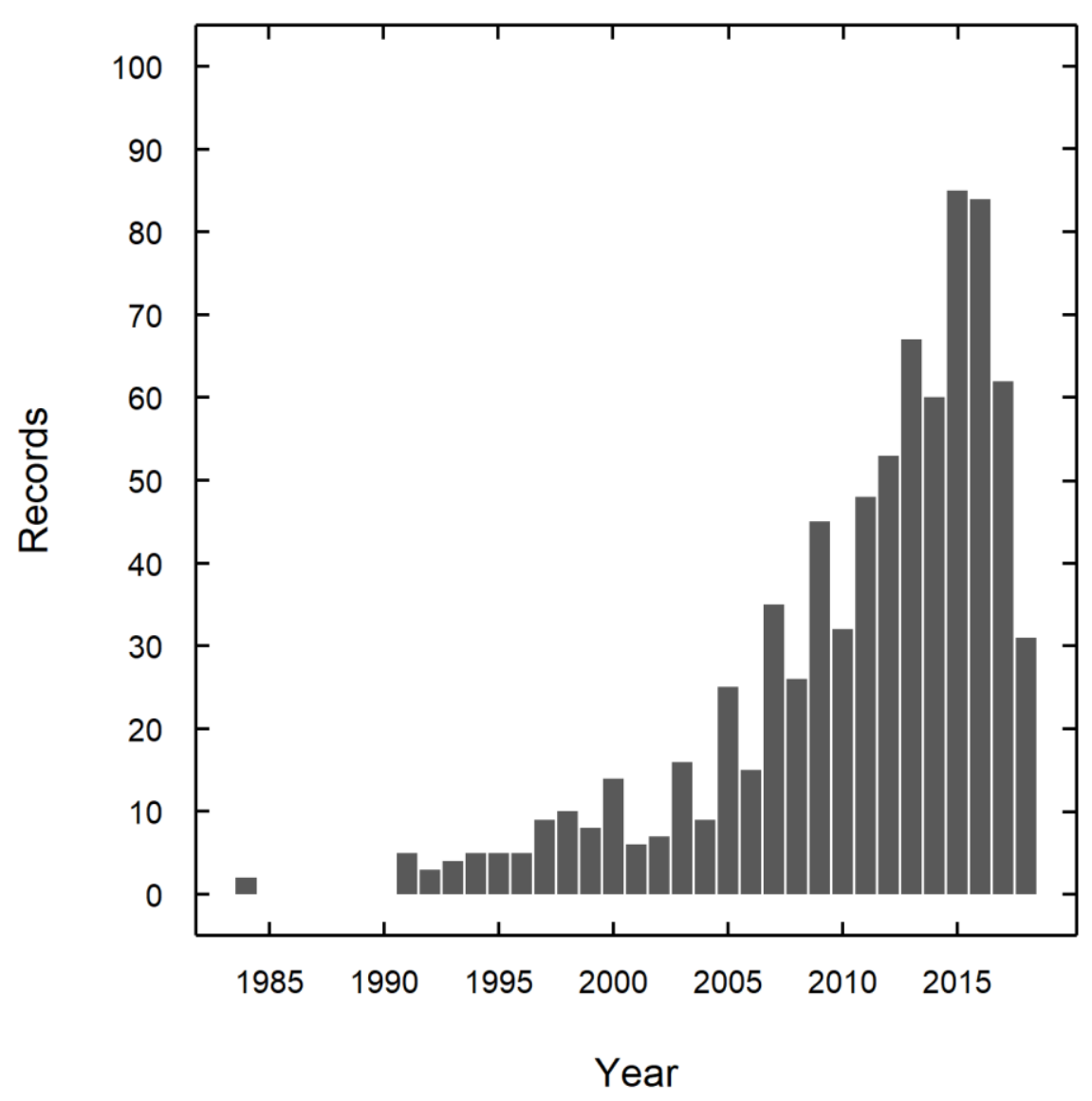

Fig. 1. An ISI Web of Science Core Collection Boolean search for "interdisciplinary AND (hazards OR disasters)” returns 776 records between 1945 and July 12, 2018. 


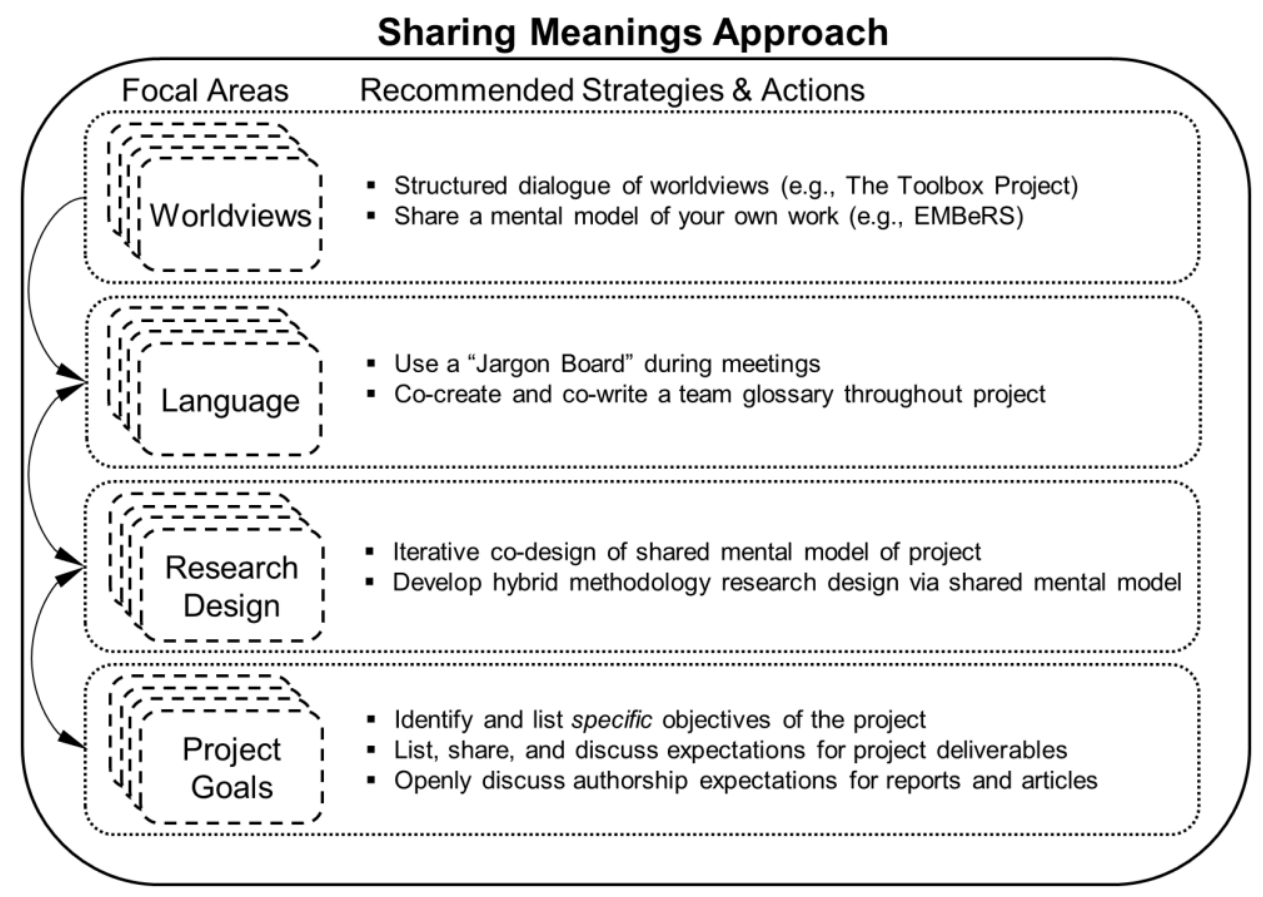

Fig. 2. A Sharing Meanings Approach is iterative in practice (arrows). Each dashed box represents each $n^{\text {th }}$ team member's meaning for each focal area. See the main text for references to the Toolbox Project and EMBeRS. 